\title{
Crystallization-Based Isolation of Pure Rutin from Herbal Extract of Sophora Japonica
}

Elena Horosanskaia' ${ }^{1}$, Minh Tan Nguyen², Dinh Tien V ${ }^{2}$, Heike Lorenz ${ }^{*}, 1$, Andreas Seidel-Morgenstern ${ }^{1}$

${ }^{1}$ Max Planck Institute for Dynamics of Complex Technical Systems, Magdeburg, Germany

${ }^{2}$ Hanoi University of Science and Technology, Hanoi, Vietnam

* Corresponding author

E-mail: Iorenz@mpi-magdeburg.mpg.de 


\section{Abstract}

Crystallization-based isolation of rutin from a plant extract of Sophora Japonica was studied. Solid-liquid equilibria of rutin were determined in methanol, ethanol and 2propanol. Solvate formation and stability were investigated using X-ray powder diffraction and thermogravimetric analysis coupled with differential scanning calorimetry. The study revealed a short-term stability of rutin ethanolate at ambient conditions in contrast to the behavior of rutin trihydrate. Based on the results obtained seeded crystallization in batch and semi-continuous operation mode was designed and successfully implemented. Crystalline rutin trihydrate of $99 \%$ purity was isolated with overall process yields of $95 \%$ and $87 \%$ in batch and semi-continuous processes respectively.

Keywords: rutin herbal extract, solid-liquid equilibria, rutin ethanol solvate formation, seeded crystallization, batch and semi-continuous operation 


\section{Introduction}

Since early mankind history humans used plants as nutriment but also trusted in their healing power. Ability of plants to provide health benefits for human beings leads back to their bioactive ingredients, so-called secondary metabolites. These are compounds, which plants store as inactive components and activate them only in case of danger (e.g. wounding, infection, natural enemies) ${ }^{1,2}$.

Nowadays around $80 \%$ of the world population use plant-based medication for the primary health care ${ }^{3}$. For many millions of people in the developing world traditional medication in particular by using herbal preparation, so called extracts, still remain the key and frequently the only available and affordable source to restore and promote their health ${ }^{4}$.

Naturally, herbal extracts include near the desired compound a number of technically unavoidable plant constituents with related molecular structures and similar physical and chemical properties. They may have a negative impact on the final separation of the target molecule from the crude mixture ${ }^{5}$. In a recent publication Horvath et al. applied a combination of two separation techniques, SMB chromatography and cooling crystallization, to isolate the anti-malarial drug artemisinin of required purity from a semisynthetic mixture ${ }^{6}$. More recently, Malwade et al. demonstrated a process for artemisinin recovery from the chromatography fractions of $A$. annua extract using antisolvent and cooling crystallization. Additionally it was found, that in the mixture present impurities do not significantly affect the crystallization process ${ }^{7}$.

The application of crystallization as the final separation step for an active pharmaceutical ingredient (API) gains in importance particularly in case of solid dosage forms. There near the purity of the crystallized product also stability of the solid state is decisive for quality of the formulated drug (dissolution rate and bioavailability $)^{8}$. Furthermore, feasibility of in- situ monitoring of the formation and transformation from the unfavorable metastable to the desired thermodynamically stable solid form of an API was demonstrated ${ }^{9,10}$.

A typical representative of a pharmaceutic relevant plant produced bioactive molecule is rutin, a flavonoid detected in more than 70 plants growing in China and Vietnam ${ }^{11}$. Recently, in their review Ganeshpurkar et al. ${ }^{12}$ after comprehensive study of 181 references highlighted the uniqueness of rutin with more than 40 therapeutic properties. Due to the broad range of biological activities, rutin represents an indispensable additive in more than 130 pharmaceutical preparations currently worldwide registered ${ }^{13,14}$.

Rutin, as a secondary plant metabolite, can be frequently found low concentrated (0.1-2.4 wt\%) in fruits and vegetables (e.g. apples, figs, tomatoes etc.) as well as in plant seeds and leaves (e.g. buckwheat, grape seeds, green tee etc.) ${ }^{15-17}$. Sofic et al. ${ }^{18}$ quantified rutin in 50 medical plants and reported the highest rutin content with $8.6 \mathrm{wt} \%$ in the leaves of rue. Couch et al. ${ }^{19}$ detected up to $22 \mathrm{wt} \%$ of 
rutin in the flower buds of in China growing Sophora japonica Leguminosae, also known as the "pagoda tree". This extraordinary high rutin content motivates to cultivate Sophora japonica L. for rutin isolation purposes. Nevertheless, frequently reported acute toxicity of entire Sophora genus, due to the high alkaloid content found in species, justifies the requirement for purity control of rutin final product, before it is utilized for pharmaceutical manufacturing ${ }^{20-25}$.

At present the plant Sophora japonica $L$. is increasingly cultivated in the Red River Delta of Northern Vietnam in particular for rutin production ${ }^{26,27}$. Yearly more than 10,000 tons of sundried flower buds are provided to nearby situated factories for rutin extraction. The established extraction procedure, operated in a batch mode, involves several process steps. Thereof two major steps are the quicklime extraction of flowers buds and precipitation in the raffinate phase. During these adjustment of the $\mathrm{pH}$-value is decisive for maximum rutin enrichment in the final extraction product. Standard upstream and downstream procedures as grinding, solid-liquid phase separation and drying are applied in addition. Finally, the dry crude extract, containing more than $75 \%$ rutin, is gained as the product.

With exception of the steamed water used for plant cells disruption at the very beginning of the extraction procedure, other process steps are performed at ambient conditions without any temperature control.

Rutin content of $22 \mathrm{wt} \%$ initially present in Sophora japonica $L$. is unusual high for secondary metabolites occurring in natural sources and undoubtedly contributes to the concentration of rutin with $75 \%$ in the final extraction product. However, the possible presence of toxic byproducts in the crude extract underlines the necessity of further purification processes.

This work was directed to design a robust, cost-efficient and on-site applicable process for recovery of pure rutin from the dry extract of Sophora Japonica $L$. produced in Vietnam, which can be operated as a successive step after the extraction procedure. With this aim the crystallization as a potential separation technique was considered. Therefor systematic solubility studies in potential solvents were carried out. By doing this, solvate formation of rutin and solid state stabilities were investigated. After deriving an appropriate purification strategy, crystallizationbased isolation of rutin has been performed both in a batch and a semi-continuous process. The achieved product purities and yields have been evaluated.

The first comprehensive study on rutin solubility dates back to 1952 . Krewson et al. ${ }^{28}$ investigated at $110^{\circ} \mathrm{C}$ dried rutin in various organic solvents as well as in aqueous solutions of solvents at room and at boiling temperatures. Authors reported very poor solubility of rutin in water with $\sim 0.01 \mathrm{wt} \%$, followed by ethanol with $\sim 0.5 \mathrm{wt} \%$ and high solubility in pyridine with $\sim 37 \mathrm{wt} \%$ at room temperature. In addition, rutin recrystallization from a mixture containing initially $97.3 \%$ of rutin in solvents ethanol, methanol, 2-propanol and acetone was investigated. With except of $98 \%$ rutin purity 
in crystalline product gained from methanol solution, other solutions studied provided crystalline rutin of $100 \%$ purity. Furthermore, after an elaborately drying procedure applied to the recrystallized rutin, the existence of rutin trisolvates in ethanol, methanol and acetone was pointed out. Jin et al. ${ }^{29}$ described the formation of rutin pentamethanol solvate and determined its three-dimensional crystal structure.

A detailed solubility study on anhydrous rutin was performed by $\mathrm{Zi}$ et al. ${ }^{30}$ utilizing eight organic solvents (water, methanol, ethanol, 1-propanol, 2-propanol, 1-butanol, acetone, and ethyl acetate). There, the lowest rutin solubility was measured in water with $0.03 \mathrm{wt} \%$ and the highest solubility in ethanol with $7.31 \mathrm{wt} \%$ at $40^{\circ} \mathrm{C}$.

Kim et al. ${ }^{31}$ studied recovery of pure rutin from a buckwheat plant. The developed process involved rutin extraction $\left(0.25 \mathrm{~L}\right.$ aqueous ethanol solution at $\left.80^{\circ} \mathrm{C}\right)$ followed by rutin enrichment via fractionated styrene-based resin column (1.6L aqueous ethanol solution) and recrystallization ( $8 \mathrm{~L}$ pure water at $4^{\circ} \mathrm{C}$ ) was developed. By this process $991 \mathrm{mg}$ of $95.4 \%$ pure rutin was gained with $92 \%$ overall yield.

\section{Materials and Methods}

\subsection{Materials used}

Fig. 1 illustrates a pathway from the plant to the crude extract containing target rutin.

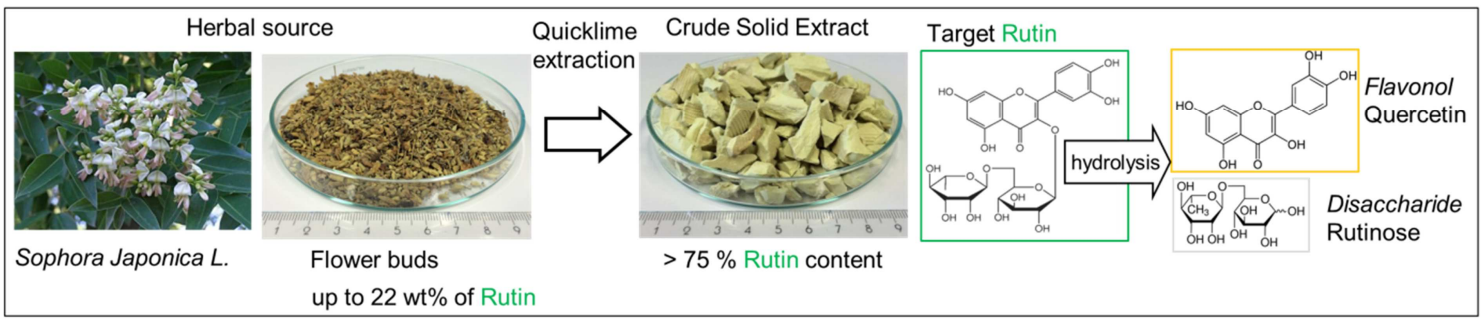

Figure 1: Bloomy Japanese pagoda tree (Sophora japonica L.), dried flower buds (22\% rutin) and dried crude extract (over $75 \%$ rutin).

Chemically rutin (Fig. 1) belongs to a group of flavonoids and represents a glycoside consisting of the flavonol quercetin and the disaccharide rutinose ${ }^{13}$. Quercetin is formed as result of hydrolysis of rutin in alkaline medium and is a major impurity in the extracted mixture.

Dried rutin crude extract was provided from collaboration partners (rutin content $>$ 75\%); standard rutin trihydrate (CAS-Nr. 250249-75-3) and standard quercetin dihydrate (CAS-Nr. 6151-25-3) purchased by Alfa Aesar GmbH \& Co. KG (both of > $97 \%$ purity) and solid rutin obtained from own recrystallization experiments from ethanol solutions. Solvents ethanol and methanol (HiPerSolv CHROMANORM, VWR $\mathrm{GmbH}$, Germany) as well as 2-propanol (LiChrosolv, Merck, Germany) were used for solubility studies. Crystallization experiments were performed in solvent ethanol of technical grade (purity < $96 \%$, VWR GmbH, Germany). 


\subsection{Analytical Techniques and Equipment}

An analytical HPLC unit (Agilent 1200 Series, Agilent Technologies Germany GmbH) was used to characterize solid standards as well as crude extract to quantify target rutin in the extract and in the final crystallization product. The method reported from $\mathrm{Zu}$ et al. $^{32}$ was modified as follows: mobile phase composition was fixed to 40/15/45/1 (v/v/v/v) methanol/acetonitrile/water/acetic acid, the flow-rate and column temperature was set to $1 \mathrm{~mL} / \mathrm{min}$ and $20^{\circ} \mathrm{C}$. Samples preliminarily dissolved in methanol were injected in the column (LUNA C18, $250 \mathrm{~mm} \times 4.6 \mathrm{~mm} ; 10 \mu \mathrm{m}$, Phenomenex $\mathrm{GmbH}$, Germany) with a volume of $1 \mu \mathrm{L}$ and analyzed at a wavelength of $254 \mathrm{~nm}$. All solid samples were prepared in methanol.

X-ray powder diffraction (XRPD) was applied to characterize the purchased solid standards, solid fractions obtained during own solubility studies as well as the crystallization products. In preparation of the measurement dry samples were ground in a mortar and introduced on the sample carrier manufactured from a Si single crystal. X-ray powder data were collected on an X'Pert Pro diffractometer (PANalytical $\mathrm{GmbH}$, Germany) using Cu-Ka radiation. Samples were scanned in a 2Theta range from 4 to $30^{\circ}$ with a step size of $0.017^{\circ}$ and a counting time of $50 \mathrm{~s}$ per step. For phase allocation in solubility studies and stability elucidation of the rutin solid phases obtained, the wet samples were prepared on the sample carrier and measured with a shortened scanning time of $22 \mathrm{~s}$ per step in a limited 2Theta range of 4 to $11^{\circ}$ with a step size of $0.033^{\circ}$.

In addition temperature-resolved XRPD measurements were made with rutin solid samples. The samples were heated stepwise from $30^{\circ} \mathrm{C}$ to $200^{\circ} \mathrm{C}$ with a heating rate of $1 \mathrm{~K} / \mathrm{min}$. At certain temperatures samples were held isothermal for a period of 15 min to allow for establishment of equilibrium before the XRPD pattern were taken. Samples were subsequently cooled down to $30^{\circ} \mathrm{C}$ with $10 \mathrm{~K} / \mathrm{min}$.

TG-DSC (Thermogravimetric analysis coupled with Differential Scanning Calorimetry) was implemented to quantify solvent molecules incorporated into the crystal structure and verify the temperature behavior of substances. The analytical devise Sensys Evo (Setaram Instrumentation, France) was used. Samples of $\sim 30 \mathrm{mg}$ were weighed in a $100 \mu \mathrm{l}$ crucible and heated from $20^{\circ} \mathrm{C}$ to $200^{\circ} \mathrm{C}$ with a constant rate of $2 \mathrm{~K} /$ min under helium atmosphere.

A multiple reactor system Crystal16 ${ }^{\mathrm{TM}}$ (Avantium Technologies BV, Amsrterdam) was used to perform polythermal solubility studies as well as to determine the metastable zone width of standard rutin trihydrate in selected solvents. Suspensions containing known excessive amount of solid in mentioned solvents were prepared in standard HPLC glass vials, equipped with magnetic stirrers and subjected to the following temperature program: starting at $5^{\circ} \mathrm{C}$, heating to $60^{\circ} \mathrm{C}$ and cooling down to $-15^{\circ} \mathrm{C}$, both with a moderate rate of $0.1 \mathrm{~K} / \mathrm{min}$. Temperatures of a "clear" and "cloud" point 
representing the saturation and nucleation temperatures were observed by means of turbidity monitoring.

More detailed solubility investigations of rutin in ethanol were performed via the classical isothermal method ${ }^{33}$. Suspensions containing purchased standard of rutin trihydrate and $5 \mathrm{~mL}$ pure ethanol were introduced in glass vials. To guarantee a continuous agitation of prepared suspensions, vials were equipped with a simple magnetic stirrer and sealed. Samples with solid in excess were placed in a thermostatic bath and allowed to equilibrate at constant temperatures between 5 and $40^{\circ} \mathrm{C}$ for at least $48 \mathrm{~h}$ under stirring. Afterwards samples of equilibrated slurries were withdrawn with a syringe and filtered through $0.45 \mu \mathrm{m}$ PTFE filter. Obtained liquid phases were analyzed for rutin content by means of HPLC. The identity of corresponding wet solid fractions was checked via XRPD. To guarantee the analyzing accuracy of solute content in liquid phases equilibrated at $5^{\circ} \mathrm{C}$, syringes and filters were precooled bevor using.

Microscopic images of crystalline rutin were taken with a digital microscope (VHX2000, Keyence, Germany) by 150 times magnification.

Finally, batch crystallization experiments were performed in a jacketed $200 \mathrm{~mL}$ glass vessel equipped with a Pt-100 resistance thermometer (resolution $0.01{ }^{\circ} \mathrm{C}$ ) connected to a thermostat (RP845, Lauda Proline, Germany) to control the system temperature. A simple magnetic stirrer was used for agitation. Furthermore, semicontinuous crystallization was implemented in a $200 \mathrm{~mL}$ jacketed reactor equipped with an overhead stirrer. At the end of the each crystallization process solid-liquid phase separation was performed using paper filters with pore sizes of $0.45 \mu \mathrm{m}$. Gained solid products were analyzed with XRPD and HPLC.

\section{Characterization of standard solids and of the crude extract}

\subsection{Analytical HPLC}

To qualify the crude extract to be purified and quantify rutin content, the sample was analyzed with HPLC. The obtained chromatogram is presented in Fig.2 and compared to those detected from rutin and quercetin standard samples. In addition the acquired rutin calibration curve is shown.

In the chromatogram recorded from crude extract only two peaks, eluting at $3.46 \mathrm{~min}$ and at $6.24 \mathrm{~min}$ can be clearly identified and assigned to rutin and quercetin, respectively.

According to the calibration curve preliminarily generated from standard rutin (Fig. 2), the amount of rutin in dry crude extract was determined to be $81 \%$. 


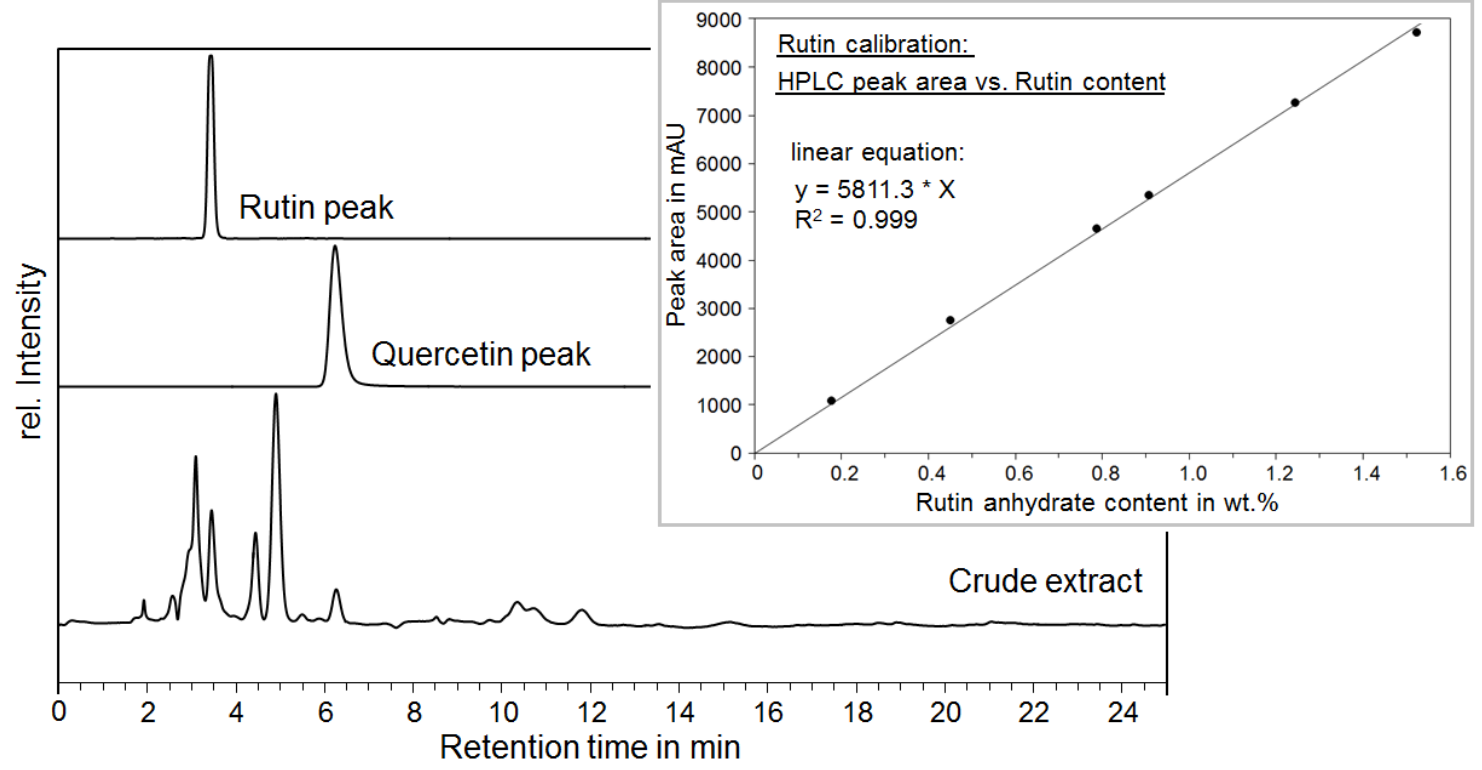

Figure 2: Analytical HPLC chromatograms of the crude extract, the target rutin and quercetin, as a potential impurity in the extract. The inset shows the rutin calibration curve.

Other peaks distinguishable in the chromatogram of crude extract were not identified. Their large number only suggests a diversity of the components present in the raw extract near the target rutin.

\subsection{XRPD and TG-DSC measurement}

The XRPD pattern recorded from dry crude extract is shown in Fig. 3 compared to that measured from a reference sample of rutin trihydrate. There was no detailed information about the crystal structure of rutin trihydrate found in the literature. Perkin ${ }^{34}$, in order to obtain an anhydrous rutin applied a complex drying procedure comprising three steps: drying over concentrated sulfuric acid during two weeks, followed by drying at $130^{\circ} \mathrm{C}$ with amyl alcohol and finally at $160^{\circ} \mathrm{C}$ with turpentine. As a result three water molecules per rutin molecule were determined. He also described the extreme hygroscopic nature of anhydrous rutin and complete conversion to rutin trihydrate within 1 hour under the air exposure.

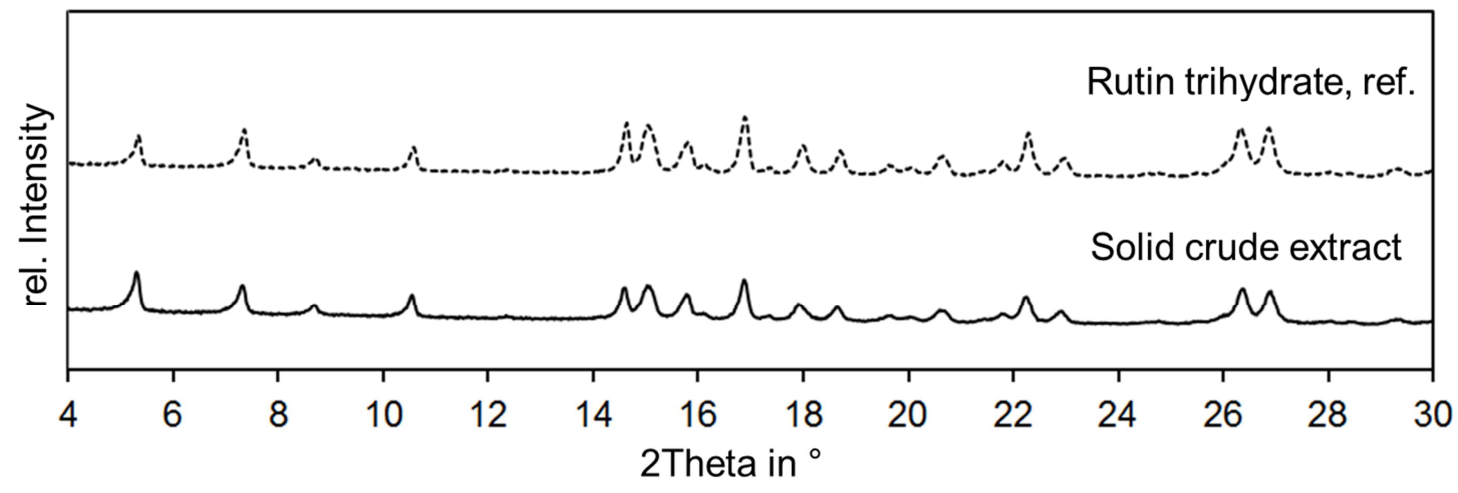


Figure 3: XRPD pattern recorded from purchased solid standard of rutin trihydrate (dashed line) and solid crude extract (solid line).

The XRPD pattern of the solid crude extract matches perfectly the one of the purchased solid standard labeled from the supplier as rutin trihydrate. Other constituents detected in the extract via HPLC could not be identified during solid phase analysis. Reasons for this may be very low contents of these components in the crude mixture or their presence in an amorphous state.

To study the temperature behavior of standard rutin trihydrate and to characterize water amount incorporated into the solid sample TG-DSC and temperature resolved XRPD analysis has been performed. The results are presented in Fig. 4.
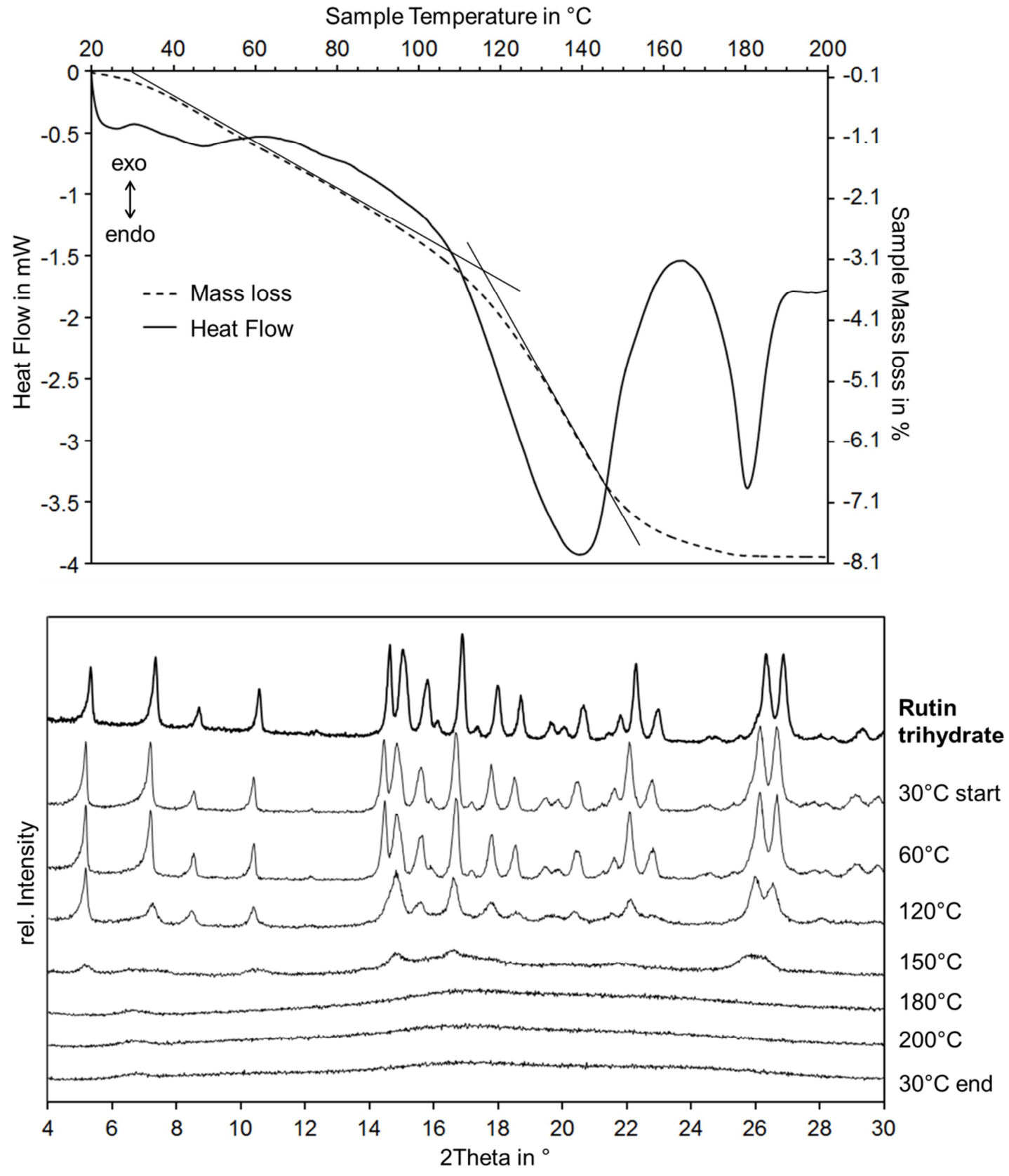
Figure 4: Upper diagram: characterization of rutin trihydrate reference sample via TG-DSC. Heat flow curve (solid line) and mass loss (dashed line) are plotted against temperature. Lower diagram: temperature-resolved XRPD measurements of the reference rutin trihydrate.

On the upper diagram the solid line reflects the heat flow and the dashed line the sample mass loss as a function of temperature. During sample heating from 20 to $200^{\circ} \mathrm{C}$ at first a broad endothermic peak with peak maximum at $138^{\circ} \mathrm{C}$ coupled with continuous mass loss is detected. The analyzed solid starts losing mass already at $21.7^{\circ} \mathrm{C}$ and stops shortly before $180^{\circ} \mathrm{C}$ with a total mass loss of $7.9 \%$. Two consecutive steps during mass loss can be recognized. During the first step (below $120^{\circ} \mathrm{C}$ ) sample lost around $3 \%$ of total mass, which correlates with the release of weakly bound one water molecule. However, apart from mass loss only barely changes of the crystalline structure of the sample could be measured (Fig. 4, XRPD pattern at $120^{\circ} \mathrm{C}$ ). Further sample heating to $200^{\circ} \mathrm{C}$ leads to sample dehydration until $180^{\circ} \mathrm{C}$ and results finally a complete amorphization of the substance. The second endothermic peak at $187^{\circ} \mathrm{C}$ does not correlate with any loss of the sample mass. The corresponding XRPD pattern at $180^{\circ} \mathrm{C}$ and $200^{\circ} \mathrm{C}$ verifies observed temperature behavior. After subsequently cooling the sample to ambient temperature still amorphous and plasticized material is presented.

The measured total mass loss of $7.9 \%$ is equivalent to the loss of three water molecules per rutin molecule, calculated to $8.13 \%$. Consequently the purchased solid standard of rutin is indeed the trihydrate form of rutin, exhibiting the recorded powder pattern (Fig. 4, upper XRPD pattern).

\section{Solubility Determination and Rutin Isolation}

\subsection{Solubility and nucleation behavior of rutin solvates (polythermal method)}

To select one suitable solvent for a crystallization process, solubility and nucleation behavior of the target compound in different solvents has to be studied using a polythermal method. Since rutin trihydrate is present in the dried crude extract and the solid phase is commercially available, it was examined in solvents ethanol, methanol and 2-propanol. Apparent saturation and nucleation temperatures observed are plotted in Fig. 5. 


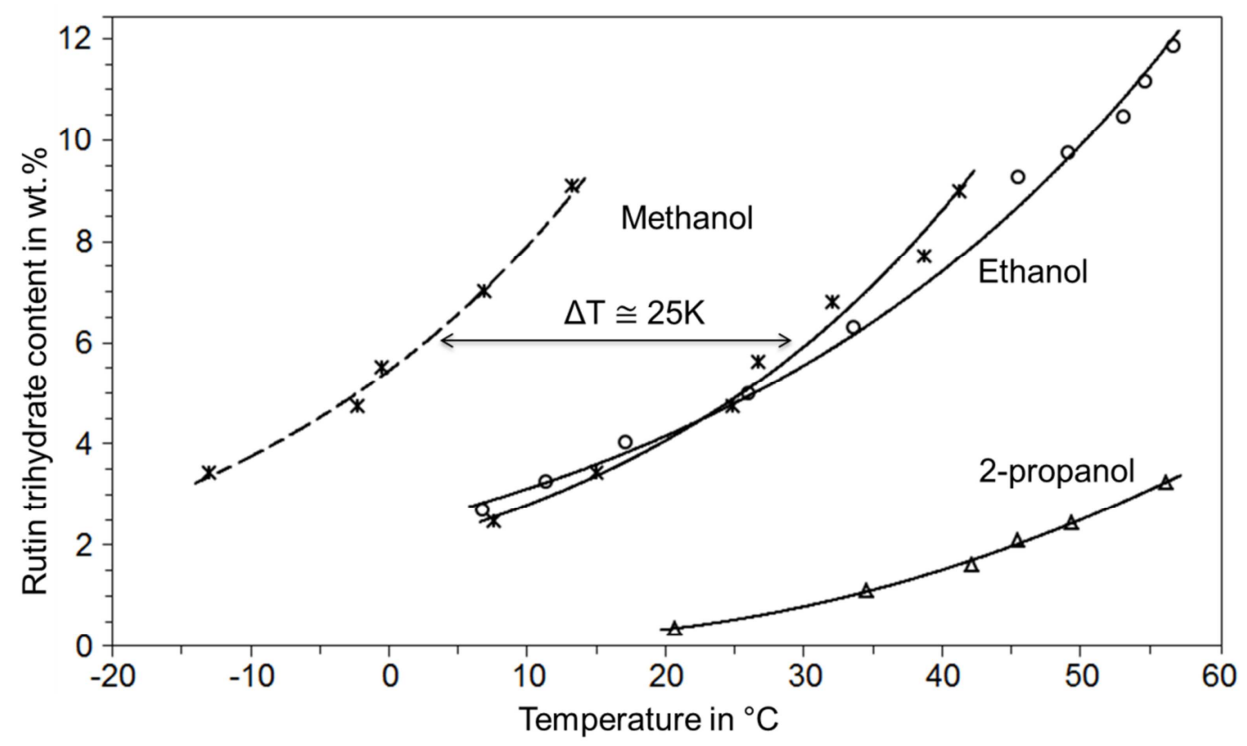

Figure 5: Apparent solubility (solid lines) of rutin trihydrate and supersolubility (dashed line) of rutin solvate in solvents methanol, ethanol, 2-propanol as a function of temperature. Metastable zone width for ethanol and 2-propanol is not represented on the graph.

Rutin trihydrate exhibits a similar solubility behavior in methanol and ethanol (Fig. 5, solid lines) with around $4 \mathrm{wt} \%$ at $20^{\circ} \mathrm{C}$ showing strong increase of solubility with rising temperature. With $0.3 \mathrm{wt} \%$ at $20^{\circ} \mathrm{C}$ and $3 \mathrm{wt} \%$ at $55^{\circ} \mathrm{C}$ the solubility of rutin trihydrate in 2-propanol is at least 3-times lower than in methanol and ethanol. For the latter solvent a weaker temperature dependence of the rutin trihydrate solubility was observed.

The width of metastable zone of an arbitrary solute in solution, i.e. the distance between solubility and supersolubility lines along the temperature axis, is determined via cooling of saturated clear solutions until the nucleation occurs. In methanol the metastable zone width was measured to approx. 25K (Fig. 5 dashed line). It should be commented; that the XRPD pattern recorded from wet solid recrystallized from methanol did not match either that from trihydrate or from pentamethanolate phase of rutin. Under consideration of results published by Krewson et $\mathrm{al}^{28}$ and Jin et al. ${ }^{29}$, the formation of a solvate phase of rutin in methanol is very probable.

During the cooling of rutin ethanol and 2-propanol solutions no primary nucleation could be observed up to $-15^{\circ} \mathrm{C}$. It can be assumed that the width of metastable zone for these solute-solvent systems exceeds $40 \mathrm{~K}$.

Due to the observed solubility trends, both methanol and ethanol can be considered as a potential solvent and 2-propanol as a potential anti-solvent for further rutin isolation via crystallization. The stronger temperature dependency of rutin solubility in methanol and ethanol, in contrast to 2-propanol, allows for higher initial product amounts and higher process yields. Nevertheless, regarding to $\mathrm{ICH}$ (International Conference on Harmonization of Technical Requirement for Registration of Pharmaceuticals for Human Use) which deals with residual solvents allowed in pharmaceutical preparations, methanol belongs to the Class 2 solvents and should 
be minimized or completely avoided during drug manufacturing. For this reason ethanol was preferred for the further investigations and process design. Due to the large metastable zone of rutin exhibiting in ethanol, seeded cooling crystallization was considered for purification of rutin from the crude extract.

\subsection{Solubility study of rutin in ethanol via classical isothermal method}

After the isothermal equilibration of rutin-ethanol suspensions at temperatures of $5^{\circ} \mathrm{C}$, $20^{\circ} \mathrm{C}$ and $40^{\circ} \mathrm{C}$, samples of saturated clear solution were taken and analyzed via HPLC. The corresponding solids were characterized via XRPD.

The determined saturation concentrations are summarized by interconnection of acquired single data points in the concentration-temperature plot in Fig. 6 (red line). In order to represent the values with that obtained from polythermal studies together on the same graph, the sample concentrations prepared initially with rutin trihydrate in ethanol were recalculated to anhydrous rutin content (Fig. 6, blue line).

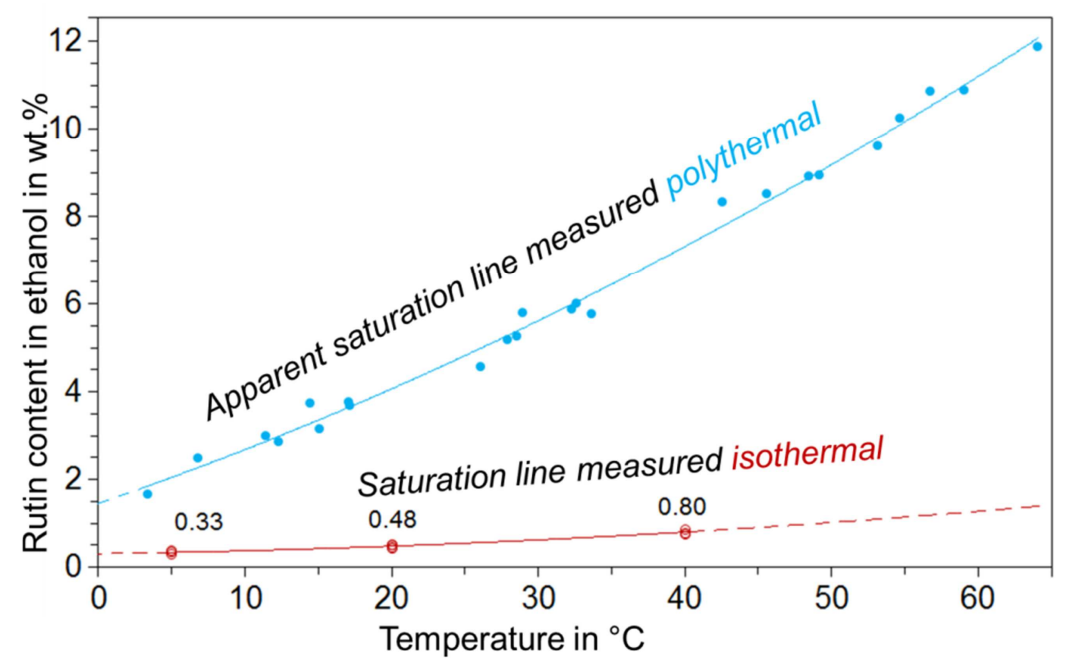

Figure 6: Solubility lines of rutin in ethanol as a function of temperature, determined during polythermal and isothermal studies.

The solubility behavior of rutin determined isothermally (Fig. 6, red line) is significantly lower than the one of rutin trihydrate observed polythermally (Fig. 6, blue line). This clearly indicates differences in these two solid phases.

The feature of organic compounds to appear in more than one crystalline form, either polymorphs or solvates, which causes different physicochemical properties (like solubility), is well known and described on numerous examples ${ }^{35}$. To clarify the differences in solubility lines observed, XRPD analyses of solid phases separated from isothermally equilibrated rutin-ethanol suspensions have been performed. Collected XRPD pattern are presented in Fig. 7 (left) together with reference diffractogram of rutin trihydrate. 
In order to visualize crystal morphology, microscopic images taken from initial solid phase of rutin trihydrate as well as from solid rutin obtained in thermodynamic equilibrium with ethanol are additionally shown in Fig. 7 (right).

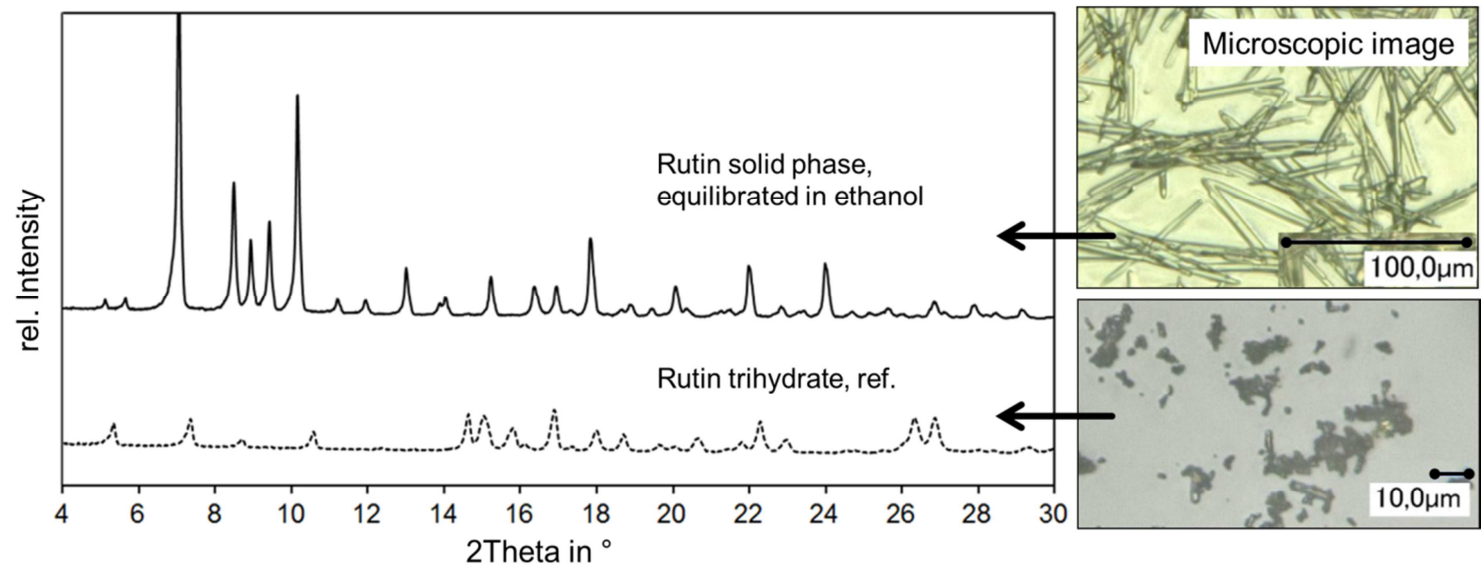

Figure 7: Left hand side: XRPD pattern recorded from rutin solid phase obtained in thermodynamic equilibrium in ethanol compared to reference diffractogram of rutin trihydrate. Right hand side: microscopic images of the rutin solid phase present after isothermal equilibration in ethanol and of standard rutin trihydrate.

Obviously, completely different diffractogram with new main peaks at smaller angles (e.g. peaks at $\sim 5^{\circ}, 5.6^{\circ}, 7^{\circ}, 8.5^{\circ}, 9^{\circ}, 9.5^{\circ}$ and $10.1^{\circ}$ ) can be recognized for rutin solid phase equilibrated in ethanol, which are not present in reference samples of rutin trihydrate.

As can be seen in the microscopic images (Fig. 7, right), long transparent needles corresponding to crystalline rutin obtained from ethanol can be easily distinguished from tiny particles of standard rutin trihydrate. Under consideration of both solubility and solid phase analysis it can be assumed, that rutin trihydrate is the solid phase that is stable at ambient conditions, while the new rutin solid phase occurred during isothermal equilibration of rutin-ethanol suspensions is thermodynamically stable phase within the studied temperature range in presence of the solvent ethanol. Since the recrystallization of rutin solvates from various solvents was already described and the three-dimensional structure of rutin pentamethanolate determined, the formation of rutin ethanol solvate is very probably. Due to a dynamic nature of polythermal solubility studies, the time is obviously not sufficient to cause a complete solid-solid phase transformation from rutin trihydrate to ethanol solvate. However, a solid-solid phase transformation partly occurred in the samples effected a slight deviation of single data points from the solubility trend line of rutin trihydrate (Fig.6, blue line).

\subsection{Stability studies of rutin solid phase formed in ethanol}

To further elucidate the stability of the crystalline rutin ethanol solvate, sold phase isolated from the rutin-ethanol suspension was subsequently introduced on the XRPD sample carrier. To track fast phase changes the single XRPD measurement 
range was shorted, scanning only the representative low 2 Theta region (from $4^{\circ}$ to $11^{\circ}$ ) within 1 min analyzing time per run. Starting with wet solid in the first run the sample was analyzed with an ultimate program including at least 4 runs in a row with duration of total 4 mins. XRPD diffractograms obtained after each of 4 runs are summarized in Fig. 8.

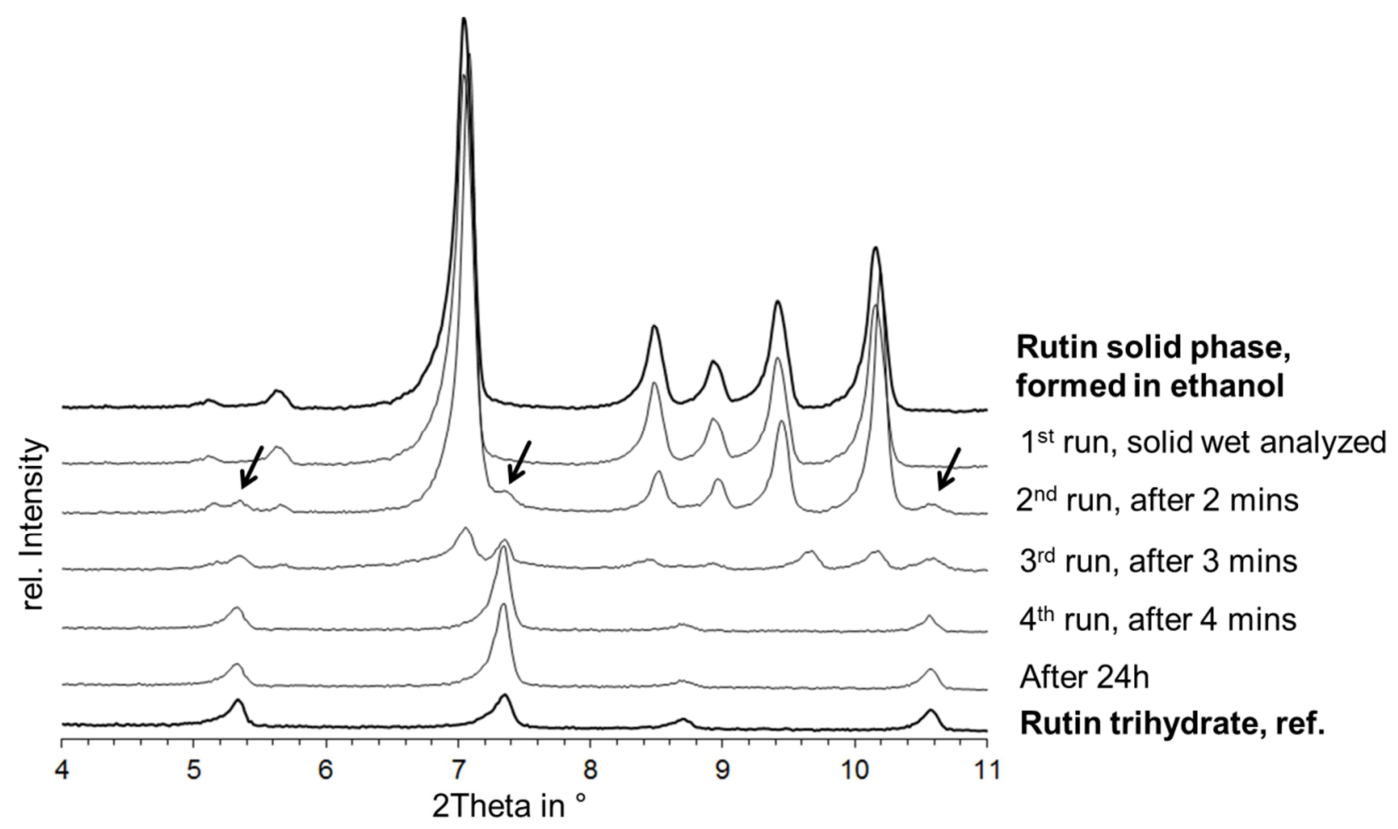

Figure 8: XRPD measurements performed on the wet rutin phase, isolated from equilibrated ethanol solution. Sample was scanned over 4 cycles within 2Theta angles from $4^{\circ}$ to $11^{\circ}$. Resulted diffractograms are compared to those recorded from reference sample of rutin trihydrate and pattern detected from rutin solid phase obtained after isothermal equilibration in ethanol.

Within the first run recorded XRPD pattern from the wet solid clearly correspond to the crystalline rutin formed at thermodynamic equilibrium in ethanol. During the second measurement a slight intensity decrease of already presented pattern is apparent. Additionally, new peaks at angles of $\sim 5.3^{\circ}, 7.3^{\circ}$ and $10.5^{\circ}$ appear, that clearly correspond to pattern of standard rutin trihydrate (lowermost diffractogram). After the third run the previously presented large peaks at 2 Theta angles (e.g. $7^{\circ}$, $8.5^{\circ}, 9^{\circ}, 9.5^{\circ}$ and $10.1^{\circ}$ ) originating from rutin ethanolate are either noticeable decreased in their size or almost disappeared. The XRPD diffractogram recorded at the end of the fourth run comprises only pattern of rutin trihydrate, which remained stable after $24 \mathrm{~h}$. Hence a complete conversion of the rutin ethanolate to rutin trihydrate, the solid phase stable at ambient conditions, was observed within only 4 minutes.

In conclusion it can be assumed, that during isothermal agitation of a suspension containing initially rutin trihydrate and ethanol, an ethanol solvate form of rutin was formed in thermodynamic equilibrium. This solvate remains stable as long as surrounding ethanol is present. On air, due to air humidity, the crystals of rutin 
ethanol solvate come into direct contact with water molecules and convert back to rutin trihydrate within a short time. The formed rutin trihydrate remains stable at ambient conditions. These observations are in accordance with investigations made by Perkin ${ }^{34}$ and Krewson et al. ${ }^{28}$.

The demonstrated short-term stability of rutin ethanol solvate at ambient conditions made it impossible to determine the exact amount of ethanol incorporated in the crystal lattice of rutin via TG-DSC analysis.

\section{Crystallization-based rutin isolation}

5.1 Design and implementation of the crystallization process for rutin separation from the crude extract (200mL scale)

Under consideration of the solid state stability of two solid forms of rutin in ethanol, three characteristic regions can be distinguished in the concentration-temperature plot, preliminarily shown in Fig.6.

Starting in the diagram at low rutin concentrations, the first region is defined by the saturation line of $\mathrm{Ru} x \mathrm{EtOH}$ and represents the unsaturated region for both forms of rutin, $\mathrm{Ru} 3 \mathrm{H}_{2} \mathrm{O}$ and $\mathrm{Ru} x \mathrm{EtOH}$. This means, that neither $\mathrm{Ru} 3 \mathrm{H}_{2} \mathrm{O}$ nor $\mathrm{Ru} \times \mathrm{EtOH}$ can be transformed from solute to solid state via seeding of a solution in the region.

The second region is limited by the saturation line of $\mathrm{Ru} \times \mathrm{EtOH}$ at the bottom and the apparent saturation line of $\mathrm{Ru} 3 \mathrm{H}_{2} \mathrm{O}$ at the top. Here $\mathrm{Ru} 3 \mathrm{H}_{2} \mathrm{O}$ still remains unsaturated. Only $\mathrm{Ru} \times \mathrm{EtOH}$ is supersaturated and can be crystallized by seeding with crystals of the same nature from ethanol solution.

Finally the third region in the concentration-temperature plot is located above both solubility lines, of $\mathrm{Ru} x \mathrm{EtOH}$ and $\mathrm{Ru} 3 \mathrm{H}_{2} \mathrm{O}$. Within the area both rutin solvates can be crystallized from the solution by seeding with the corresponding solid form, either $\mathrm{Ru} \times \mathrm{EtOH}$ or $\mathrm{Ru} 3 \mathrm{H}_{2} \mathrm{O}$. However, the rutin ethanol solvate is the only solid phase remaining stable in surrounding of ethanol. As introducing seeds of $\mathrm{Ru} 3 \mathrm{H}_{2} \mathrm{O}$ into the supersaturated ethanol solution, solvent mediated solid-solid phase transformation from the unstable seeded $\mathrm{Ru} 3 \mathrm{H}_{2} \mathrm{O}$ to the stable $\mathrm{Ru} x \mathrm{xtOH}$ occur within few minutes. Consequently, rutin ethanol solvate is the only solid phase present in the product suspension at the end of the process.

Based on solubility behavior observed, the crystallization process can be performed in two steps. The first step serves to provide a high concentrated ethanol solution in order to gain high product mass. Therefor a clear unsaturated solution from crude extract containing $>6 \mathrm{wt}$. $\%$ of rutin trihydrate in ethanol will be prepared at $50^{\circ} \mathrm{C}$. The second step is the crystallization step. Here the prepared working solution will be cooled down to $25^{\circ} \mathrm{C}$ and seeded with an ethanol suspension containing $\mathrm{Ru} x \mathrm{xtOH}$.

Due to the extraordinary weak temperature dependency of rutin ethanolate solubility, the cooling of seeded solution does not increase the process yield. For this reason 
the second crystallization process step will be performed at constant temperature of $25^{\circ} \mathrm{C}$.

First rutin separation experiment using seeded batch crystallization was performed as follows: $10.0 \mathrm{~g}$ of powdered crude extract were introduced in $120.0 \mathrm{~g}$ ethanol, so that the solution contains $7.7 \mathrm{wt} \%$ total solids content or rather $6.2 \mathrm{wt} \%$ of anhydrous rutin. While stirring the suspension was heated to $50^{\circ} \mathrm{C}$ to ensure complete dissolution of the solids. By doing this around $3.2 \%$ of impurities could not be dissolved in ethanol and were removed from the remaining hot liquid via filtration. The obtained clear solution was transferred into a $200 \mathrm{~mL}$ jacketed glass vessel to perform the actual separation process. The system temperature in the crystallizer was set to $25^{\circ} \mathrm{C}$ and held constant during the entire crystallization process. To induce the process $1 \mathrm{~mL}$ of seed suspension containing rutin ethanol solvate in ethanol was introduced into the supersaturated clear solution.

Already after 30 minutes formation of a yellow pasty mass (Fig. 9) with a very high suspension density was observed, which was almost impossible to agitate. For this reason the process was stopped, the solid-liquid phase separation was performed and solid product was analyzed via XRPD and via HPLC.

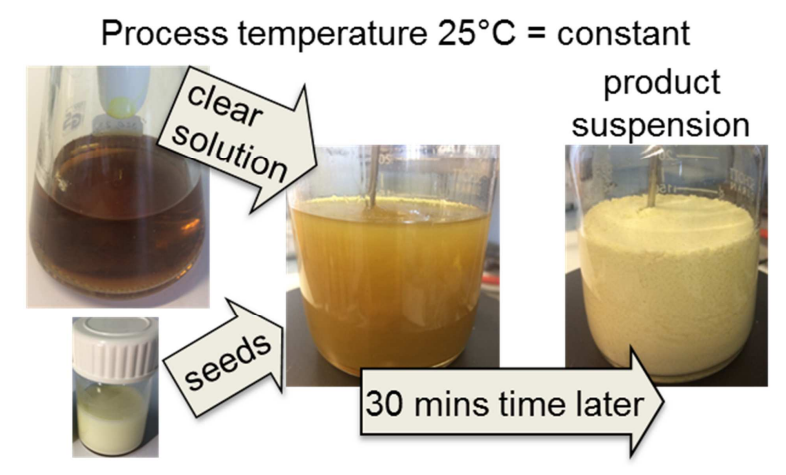

Figure 9: Seeded solution and finally gained product suspension.

During the filtration of the product suspension a slight change in yellow color of the filter cake was observed (Fig. 10).
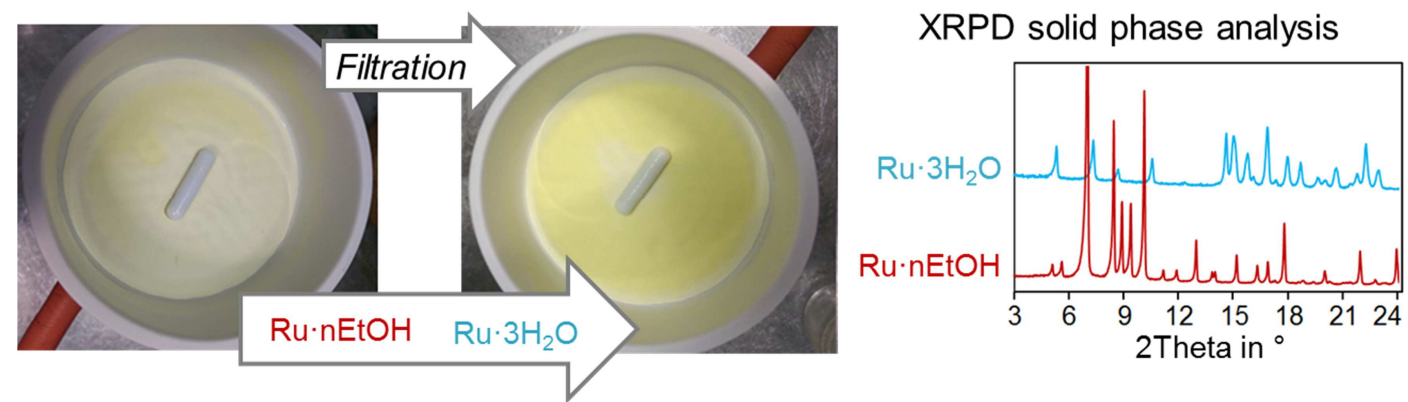

Figure 10: Left hand side: solid-solid phase transformation from rutin ethanol solvate to rutin trihydrate while filtration of the product suspension. Right hand side: XRPD analysis of gained crystalline product in wet environment (red) and after filtration. 
Parallel performed XRPD measurements of corresponding solids (Fig. 10) clearly demonstrate that the color changes of the filter cake are connected with the solidsolid phase transformation from initially crystallized rutin ethanol solvate (red powder pattern) to finally stable rutin trihydrate (blue powder pattern) as described in section 4.3 above. The HPLC measurements of the final product provided a chromatogram (Fig. 11) representing a single peak, which can be clearly assigned to the target rutin.

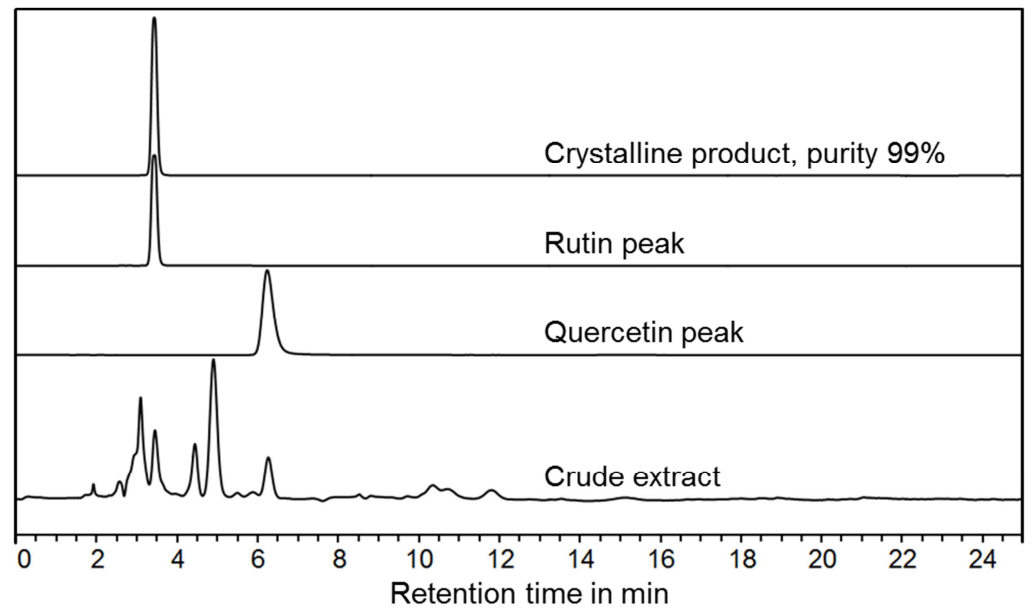

Figure 11: Analytical HPLC chromatograms of the final crystalline product compared to crude extract, target rutin and impurity quercetin.

During the crystallization process described $8.40 \mathrm{~g}$ of rutin trihydrate with purity higher than $99 \%$ were recovered from the crude extract with a yield of $95 \%$ relating to $8.75 \mathrm{~g}$ rutin trihydrate present initially in the crude extract.

In order to establish a mass balance of total solids utilized during the process, solvent ethanol was completely removed from filtered mother liquor via evaporation and amount of residual solid fraction was taken into account. Table 1 gives a brief overview of the crystallization process results.

Table 1: Results overview of rutin isolation from the crude extract via crystallization

\begin{tabular}{|c|c|c|}
\hline Parameter & $\begin{array}{l}\text { Initial } \\
\text { Amount }\end{array}$ & $\begin{array}{l}\text { Final } \\
\text { Amount }\end{array}$ \\
\hline Ethanol & $120 \mathrm{~g}$ & \\
\hline Crude extract, solid & $10.0 \mathrm{~g}$ & \\
\hline Total solids content & 7.7 wt\% & \\
\hline $81 \%$ anhydrous rutin & $8.1 \mathrm{~g} / 6.2 \mathrm{wt} \%$ & \\
\hline $87.58 \% \mathrm{Ru} 3 \mathrm{H}_{2} \mathrm{O}$ & $8.75 \mathrm{~g}$ & \\
\hline Non-dissolved impurity fraction & & $0.32 \mathrm{~g} / 3.2 \%$ \\
\hline Crystalline product & & $8.40 \mathrm{~g}$ \\
\hline Purity / target content & & $99 \% / 8.32 \mathrm{~g}$ \\
\hline Yield (m(product pure target) / m(initial $\mathrm{Ru} 3 \mathrm{H}_{2} \mathrm{O}$ )*100\%) & & $96 \%$ \\
\hline Solid residual in mother liquor & & $1.22 \mathrm{~g}$ \\
\hline
\end{tabular}

Mass balance (solids)

$10.0 \mathrm{~g}$

$\Sigma 9.94 \mathrm{~g}$ 
As a conclusion it can be summarized, that a designed process for rutin separation from herbal extract, was successfully implemented as a seeded isothermal crystallization in a batch mode. The process provided in one crystallization step a $99 \%$ pure target rutin trihydrate, the crystalline phase stable at ambient conditions.

The high dense product suspension appeared shortly after startup of the process made the stirring and further downstream processes extraordinary challenging. This was obviously caused by the extremely high supersaturation of rutin ethanol solvate in the working solution. To quantify a value of the relative supersaturation $\sigma$ of $R u$ $\mathrm{xEtOH}$ in ethanol solution following equation can be applied. According to Mersmann ${ }^{36}$ and Mullin ${ }^{37}$ relative supersaturation $\sigma$ for arbitrary target compound in solution is generally defined as $\sigma=\Delta C / C^{*}\left(T^{*}\right)$, where $\Delta C=\left(C_{\text {START }}\left(T_{\text {START }}\right)-C^{*}\left(T^{*}\right)\right.$, with $\mathrm{C}_{\text {START }}$ ( TSTART $_{\text {ST }}$ actual target concentration in solution at the beginning of the process and $C^{*}\left(T^{*}\right)$ equilibrium solubility value of the target at temperature $T^{*}$.

In case of rutin ethanol solvate ( $\mathrm{Ru} x \mathrm{EtOH})$ as a solid to be crystallized, the relative supersaturation was calculated using $\mathrm{C}_{\text {START }}\left(\mathrm{T}=50^{\circ} \mathrm{C}\right)=6.2 \mathrm{wt} \%$ and $\mathrm{C}^{*}\left(\mathrm{~T}=25^{\circ} \mathrm{C}\right)=$ $0.5 \mathrm{wt} \%$ to $\sigma(\mathrm{Ru} \times \mathrm{EtOH})=11.4$. As Hofmann ${ }^{38}$, an optimal crystallization process is performed for the value of relative supersaturation $0.8<\sigma<1$. For values of $\sigma>10$ the crystallization process cannot be controlled and a nucleation shower takes place.

In order to enable easy handling of product suspensions in downstream as well as to maximize the overall process yield, an optimal start value of relative supersaturation of Ru xEtOH was defined, based on empiric studies.

\subsection{Optimization of relative supersaturation value for Ru xEtOH crystallization}

Solutions of crude extract in ethanol with an initial rutin contents C START $_{\text {S }} 5 \mathrm{wt} \%$, $3 \mathrm{wt} \%$ and $2 \mathrm{wt} \%$ and corresponding relative supersaturations $\sigma$ of 9,5 and 3 with respect to rutin ethanol solvate were prepared. The crystallization procedure preliminarily implemented on solution with initial rutin content of $6.2 \mathrm{wt} \%$ was repeated.

It can be summarized, that with regard to product quality and process yield all of four crystallization experiments performed on solutions with initial rutin contents between $2 \mathrm{wt} \%$ and $6.2 \mathrm{wt} \%$ in ethanol provided satisfactory results with product purities of $99 \%$ and overall process yields of approximately 95\%. Nevertheless, only the

solution with the lowest initial rutin content of $2 \mathrm{wt} \%$ in ethanol and relative supersaturation of 3 provided a product suspension of favorable characteristics with particles showing a tendency to settle down, which were easy to agitate, pump and filter.

\subsection{Semi-continuous crystallization process for rutin separation (200mL scale)}

Despite the versatility of batch crystallization processes frequently used for isolation of APl's, the continuous operation mode becomes more and more attractive in 
pharmaceutical industry in terms of high material throughput, consistent and costefficient production ${ }^{39-42}$.

Since the rutin extraction from the plant source is applied in a batch mode, investigation of fully continuously process for production of pure crystalline rutin is not at primary focus at present stage of development. In this section feasibility of a rutin separation via a semi-continuous crystallization process was studied. To simulate a semi-continuous process in the lab scale, a model experiment was built up. Therefor a periodic product withdrawal from the crystallizer into the product suspension tank with parallel addition of crude solution from the feed tank was applied (Fig. 12).

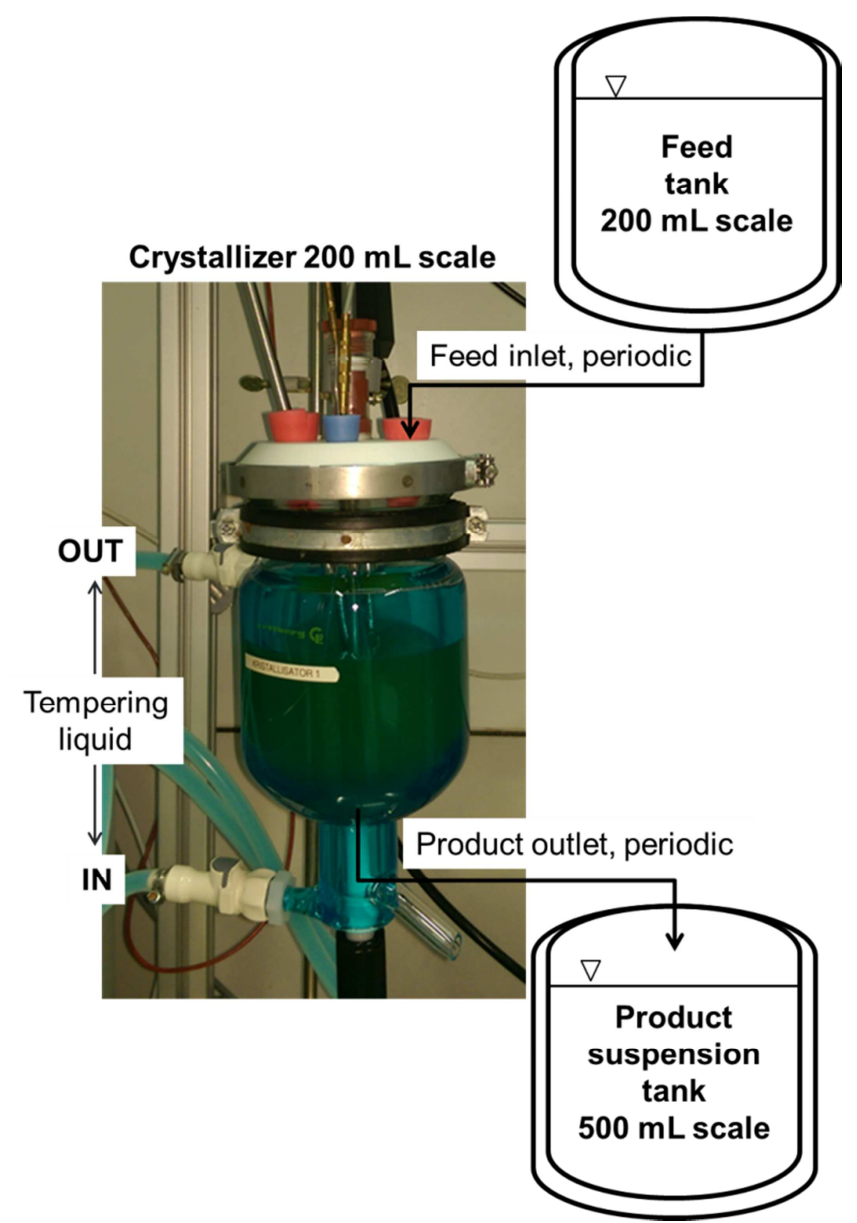

Figure 12: Buildup of the semi-continuous crystallization process in a $200 \mathrm{~mL}$ jacketed crystallizer, periodic feed addition and product suspension.

Two equal clear solutions, a startup and a feed solution, with 2 wt $\%$ of initial anhydrous rutin content were prepared, by dissolving of $3.05 \mathrm{~g}$ of solid crude extract in $120 \mathrm{~g}$ ethanol at $50^{\circ} \mathrm{C}$. Afterwards a fraction of non-dissolved impurities $(3.6 \%$ and $3.3 \%$ ) was separated from residual clear solution, which represents the crude solution for the crystallization process. An overview of utilized amounts is given in Table 2.

Table 2: Solution preparation for the semi-continuous crystallization mode. 


\section{Solution}

\begin{tabular}{ll} 
Start Parameter & Amount \\
\hline Ethanol & $120 \mathrm{~g}$ \\
Crude extract solid & $3.05 \mathrm{~g}$ \\
Total solids content & $2.48 \mathrm{wt} \%$ \\
$87.58 \% \mathrm{Ru} 3 \mathrm{H}_{2} \mathrm{O}$ & $2.67 \mathrm{~g}$ \\
$81 \%$ anhydrous rutin & $2.47 \mathrm{~g} / 2.01 \mathrm{wt} \%$ \\
Non-dissolved impurity fraction & $0.11 \mathrm{~g} / 3.6 \%$
\end{tabular}

To start up the crystallization, one crude solution was introduced into the crystallizer and under agitation $1 \mathrm{~mL}$ of seeds suspension, containing rutin ethanol solvate in ethanol was added at constant temperature of $25^{\circ} \mathrm{C}$. After passing of 30 mins a first fraction of the gained product suspension (around $40 \mathrm{~mL}$ ) was withdrawn from crystallizer into the product tank. Subsequently an equal volume of the crude solution (around $40 \mathrm{~mL}$ ) was added from the feed tank to the crystallizer to reach the initial solution level. Since the residual product suspension in the vessel acts as seeds for the added fresh feed solution, the crystallization process can be consequently continued and no further seeding is required. Afterwards every 30 mins $40 \mathrm{~mL}$ of product suspension were removed from the crystallizer and subsequently replaced by equal amount of fresh feed solution. This procedure was repeated as long as beforehand prepared feed solution in the feed tank was completely consumed. At the end of the last process step the crystallizer was emptied and the residual fraction of product suspension produced was moved to the corresponding tank. The entire collected product suspension was filtered. Thus obtained crystalline product was dried at $40^{\circ} \mathrm{C}$ in an oven, weighted and analyzed for purity and overall yield. To generate again a mass balance of all solids present in the solution during the whole process, ethanol was completely removed from the filtered mother liquor via evaporation and the amount of residual solid fraction was analyzed. Summary of the results of the studied semi-continuous separation process is given in Table 3 .

Table 3: Results overview of rutin isolation from the crude extract via a semi-continuous crystallization process

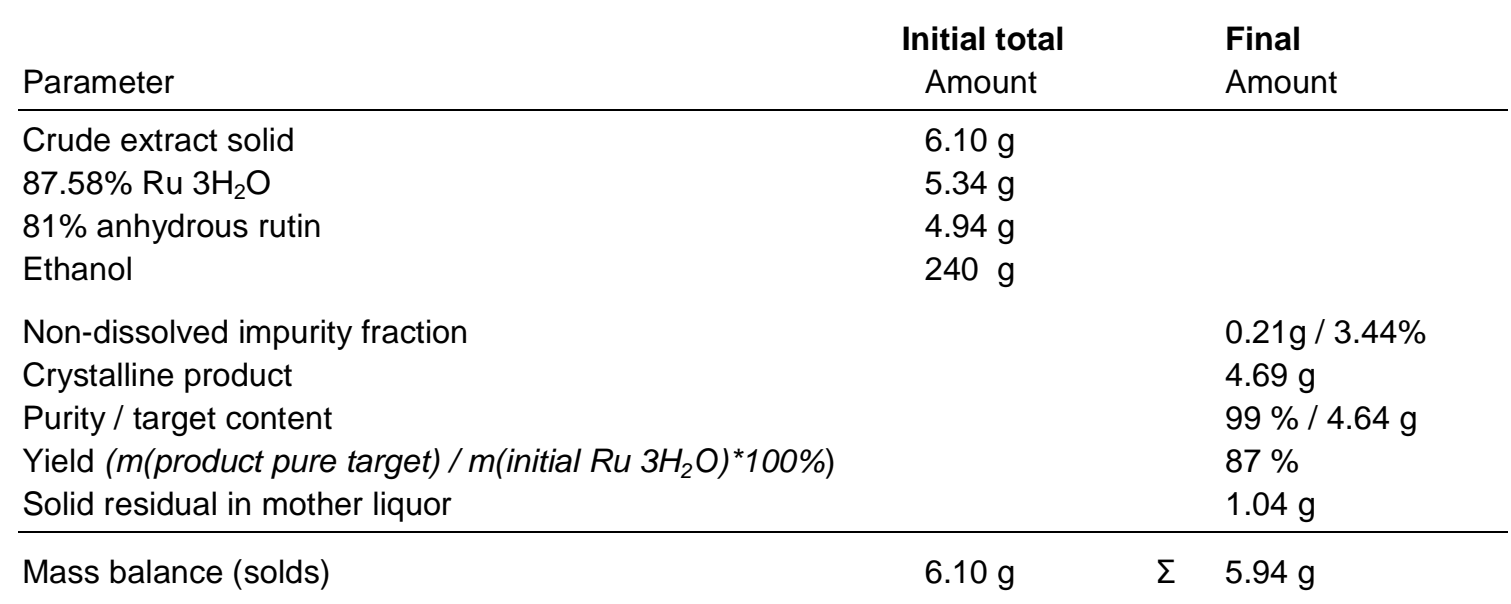


At the end of the crystallization process, operated in a semi-continuous mode, $4.69 \mathrm{~g}$ of rutin trihydrate was collected with purity higher than $99 \%$ and a yield of $87 \%$ related to $6.10 \mathrm{~g}$ rutin trihydrate present initially in the crude extract.

The crystallization process described have been patented by the same authors ${ }^{43}$.

\section{Conclusions and Summary}

During this work a comprehensive study on solubility and supersolubility of rutin trihydrate in solvents methanol, ethanol and 2-propanol was performed. In addition the formation of rutin ethanolate in ethanol was investigated. The study confirms a short-term stability of rutin ethanolate at ambient conditions in contrast to rutin trihydrate, described in literature ${ }^{28,34}$. Based on the determined solid-liquid equilibria, a seeded isothermal crystallization in batch and semi-continuous operation mode was designed and successfully implemented. Both processes provided crystalline rutin trihydrate with identical high purity of $99 \%$ and a satisfactory overall process yield $96 \%$ and $87 \%$ respectively. During the semi-continuous operation mode a small part of target rutin could not be completely recovered from the crude mixture and remained in the mother liquor, which caused a lower process yield. Here, to improve the overall process yield, the residence time of seeds crystals in the vessel should be further optimized.

The developed crystallization-based separation process represents an attractive perspective for production of pure crystalline rutin from a plant extract of Vietnamese Sophora Japonica L., which can be operated on-site as a successive step after the extraction procedure. The comparatively simple but also very robust, safety and costefficient crystallization process provides reproducibly in the product stream $99 \%$ pure rutin trihydrate, without a rigorous control of process temperature.

\section{Acknowledgements}

We thank Jacqueline Kaufmann and Stefanie Leuchtenberg (Max Planck Institute for Dynamics of Complex Technical Systems, Magdeburg, Germany) for supporting the analytical work. 


\section{References}

1. Phillipson, J. D., Phytochemistry and medicinal plants. Phytochemistry 2001, 56, 237-43.

2. Azmir, J., Zaidul, I. S. M., Rahman, M. M., Sharif, K. M., Mohamed, A., Sahena, F., Jahurul, M. H. A., Ghafoor, K., Norulaini, N. A. N., Omar, A. K. M., Techniques for extraction of bioactive compounds from plant materials: A review. Journal of Food Engineering 2013, 117, 426-436.

3. Kamboj, V. P., Herbal medicine. Current Science 2000, 78, 35-39.

4. Houghton, P. J., Old yet new - Pharmaceuticals from plants. Journal of Chemical Education 2001, 78, 175-184.

5. Handa, S. S., Khanuja, S.P.S., Longo, G., Rakesh, D.D., Extraction Technologies for Medicinal and Aromatic Plants. ICS-UNIDO: Trieste, Italy, 2008.

6. Horváth, Z., Horosanskaia, E., Lee, J.W., Lorenz, H., Gilmore, K., Seeberger, P.H., Seidel-Morgenstern, A., Recovery of Artemisinin from a Complex Reaction Mixture Using Continuous Chromatography and Crystallization. Organic Process Research \& Development 2015, 19, 624-634.

7. Malwade, C. R.; Buchholz, H.; Rong, B.-G.; Qu, H.; Christensen, L. P.; Lorenz, H.; Seidel-Morgenstern, A., Crystallization of Artemisinin from Chromatography Fractions ofArtemisia annuaExtract. Organic Process Research \& Development 2016, 20, 646-652.

8. Beckmann, W., Crystallization of Pharmaceutical Compounds Polymorphs, Pseudo-Polymorphs and Particle Formation. Engineering in Life Sciences 2003, 3, 113-120.

9. O'Sullivan, B., Barrett, P., Hsiao, G., Carr, A., Glennon, B., In Situ Monitoring of Polymorphic Transitions. Organic Process Research \& Development 2003, 7, 977982.

10. Su, W., Hao, H., Barrett, M., Glennon, B., The Impact of Operating Parameters on the Polymorphic Transformation ofd-Mannitol Characterized in Situ with Raman Spectroscopy, FBRM, and PVM. Organic Process Research \& Development 2010, $14,1432-1437$.

11. Humphreys, F. R., The occurrence and industrial production of Rutin in Southeastern Australia. Economic Botany 1964, 18, 195-253.

12. Ganeshpurkar, A.; Saluja, A. K., The Pharmacological Potential of Rutin. Saudi Pharm J 2017, 25, 149-164.

13. Chua, L. S., A review on plant-based rutin extraction methods and its pharmacological activities. J Ethnopharmacol 2013, 150, 805-17.

14. Birt, D. F.; Hendrich, S.; Wang, W., Dietary agents in cancer prevention: flavonoids and isoflavonoids. Pharmacol Ther 2001, 90, 157-77.

15. Jiang, P.; Burczynski, F.; Campbell, C.; Pierce, G.; Austria, J. A.; Briggs, C. J., Rutin and flavonoid contents in three buckwheat species Fagopyrum esculentum, F. tataricum, and F. homotropicum and their protective effects against lipid peroxidation. Food Research International 2007, 40, 356-364.

16. Veberic, R.; Colaric, M.; Stampar, F., Phenolic acids and flavonoids of fig fruit (Ficus carica L.) in the northern Mediterranean region. Food Chemistry 2008, 106, 153-157.

17. Stewart, A. J.; Bozonnet, S.; Mullen, W.; Jenkins, G. I.; Lean, M. E.; Crozier, A., Occurrence of flavonols in tomatoes and tomato-based products. $J$ Agric Food Chem 2000, 48, 2663-9. 
18. Sofic, E.; Copra-Janicijevic, A.; Salihovic, M.; Tahirovic, I.; Kroyer, G., Screening of medicinal plant extracts for quercetin-3rutinoside (rutin) in Bosnia and Herzegovina. Medicinal Plants - International Journal of Phytomedicines and Related Industries 2010, 2, 97.

19. Couch, J. F.; Naghski, J.; Krewson, C. F., Rutin Content of Sophora japonica L. Journal of the American Chemical Society 1952, 74, 424-425.

20. Briggs, L. H.; Ricketts, J., Sophora alkaloids. Part I. The alkaloids of the seeds of S. microphylla, Ait. J Chem Soc 1937, 1795-1798.

21. Briggs, L. H.; Russell, W. E., Sophora alkaloids. Part III. The alkaloids of the seeds of S. chrysophylla. J Chem Soc 1942, 507.

22. Briggs, L. H.; Russell, W. E., Sophora alkaloids. Part IV. The alkaloids from the seeds of the Chatham Islands species. Journal of the Chemical Society (Resumed) 1942, 555.

23. Briggs, L. H.; Taylor, W. S., Sophora alkaloids. Part II. The alkaloids of the seeds of S-tetraptera. J Chem Soc 1938, 1206-1207.

24. Harrisson, J. W. E.; Seltzer, B. W.; Martin, E. W., The spectrophotometric examination and acute toxicity of rutins obtained from Fagopyrum esculentum (buckwheat) and Sophora japonica. Journal of the American Pharmaceutical Association (Scientific ed.) 1950, 39, 556-559.

25. Ng, S. W.; Ching, C. K.; Chan, A. Y.; Mak, T. W., Simultaneous detection of 22 toxic plant alkaloids (aconitum alkaloids, solanaceous tropane alkaloids, sophora alkaloids, strychnos alkaloids and colchicine) in human urine and herbal samples using liquid chromatography-tandem mass spectrometry. $J$ Chromatogr $B$ Analyt Technol Biomed Life Sci 2013, 942-943, 63-9.

26. Linh, H. T., Natural Dyes in Eastern Asia (Vietnam and Neighbouring Countries). In Handbook of Natural Colorants, Bechtold, T. M., R., Ed. John Wiley \& Sons, Ltd.2009; pp 65-72.

27. Nguyen Thi Thu Huyen, P. D. C., Pham Van Thiem, The composition of fruit essential oil and extract of dried bud of Sophora japonica I. cultivated in Vietnam. Journal of Science \& Technology 2009, 75A, 79-82.

28. Krewson, C. F.; Naghski, J., Some Physical Properties of Rutin. J Am Pharm Assoc Sci 1952, 41, 582-587.

29. Jin, G.-Z.; Yamagata, Y.; Tomita, K.-i., Structure of rutin pentamethanol. Chemical \& Pharmaceutical Bulletin 1990, 38, 297-300.

30. Zi, J.; Peng, B.; Yan, W., Solubilities of rutin in eight solvents at $\mathrm{T}=283.15$, 298.15, 313.15, 323.15, and 333.15K. Fluid Phase Equilibria 2007, 261, 111-114.

31. Kim, K. H., Lee, K.W., Kim, D.Y., Park, H.H., Kwon, I.B., Lee, H.J., Optimal recovery of high-purity rutin crystals from the whole plant of Fagopyrum esculentum Moench (buckwheat) by extraction, fractionation, and recrystallization. Bioresour Technol 2005, 96, 1709-12.

32. Zu, Y.; Li, C.; Fu, Y.; Zhao, C., Simultaneous determination of catechin, rutin, quercetin kaempferol and isorhamnetin in the extract of sea buckthorn (Hippophae rhamnoides L.) leaves by RP-HPLC with DAD. J Pharm Biomed Anal 2006, 41, 7149.

33. Lorenz, H., Solubility and Solution Equilibria in Crystallization. In Crystallisation: Basic Concepts and Industrial Application, 1st ed.; Beckmann, W., Ed. Wiley-VCH Verlag GmbH \& Co. KGaA: Weinheim, Germany, 2013; pp 35-74.

34. Perkin, A. G., Robinin, violaquercetin, myrticolorin, and osyritrin. J Chem Soc 1902, 81, 473-480. 
35. Hilfiker, R., Polymorphism of Crystalline Systems. In Crystallisation: Basic Concepts and Industrial Application, 1st ed.; Beckmann, W., Ed. Wiley-VCH: WileyVCH Verlag GmbH \& Co. KGaA., 2013; pp 85-103.

36. Mersmann, A., Crystallization Technology Handbook. 2nd ed.; Marcel Dekker, Inc.: New York, 2001; p 840.

37. Mullin, J. W., Crystallization. 4 ed.2001.

38. Hofmann, G., Kristallisation in der industriellen Praxis. WILEY-VCH Verlag GmbH \& Co. KGaA, Weinheim, 2004; p 275.

39. Wieckhusen, D., Development of Batch Crystallizations. In Crystallization: Basic Concepts and Industrial Applications, 1st ed.; Beckmann, W., Ed. Wiley-VCH Verlag GmbH \& Co. KGaA: Weinheim, Germany, 2013; p 16.

40. Schaber, S. D.; Gerogiorgis, D. I.; Ramachandran, R.; Evans, J. M. B.; Barton, P. I.; Trout, B. L., Economic Analysis of Integrated Continuous and Batch Pharmaceutical Manufacturing: A Case Study. Industrial \& Engineering Chemistry Research 2011, 50, 10083-10092.

41. O'Brien, A. G.; Horvath, Z.; Levesque, F.; Lee, J. W.; Seidel-Morgenstern, A.; Seeberger, P. H., Continuous synthesis and purification by direct coupling of a flow reactor with simulated moving-bed chromatography. Angew Chem Int Ed Engl 2012, 51, 7028-30.

42. Su, Q.; Nagy, Z. K.; Rielly, C. D., Pharmaceutical crystallisation processes from batch to continuous operation using MSMPR stages: Modelling, design, and control. Chemical Engineering and Processing: Process Intensification 2015, 89, 4153.

43. Horosanskaia, E., Lorenz, H., Seidel-Morgenstern, A., Nguyen Minh Tan, Vu Dinh Tien, Method for purifying Rutin. VN 1-2016-01852, July 25, 2016. 